\title{
Journal of Extracellular Vesicles
}

\section{Response to letter to the editor}

\section{G. Rikkert, R. Nieuwland, L. W. M. M. Terstappen \& F. A. W. Coumans}

To cite this article: L. G. Rikkert, R. Nieuwland, L. W. M. M. Terstappen \& F. A. W. Coumans (2019) Response to letter to the editor, Journal of Extracellular Vesicles, 8:1, 1648997, DOI: 10.1080/20013078.2019.1648997

To link to this article: https://doi.org/10.1080/20013078.2019.1648997
(2) 2019 The Author(s). Published by Informa UK Limited, trading as Taylor \& Francis Group on behalf of The International Society for Extracellular Vesicles.

\section{Published online: 05 Aug 2019.}

Submit your article to this journal $\widetilde{1}$

Џ Article views: 703

Q View related articles $\longleftarrow$

$\bigoplus_{\text {Crossmatk }}$ View Crossmark data $\sqsubset \nearrow$




\section{Response to letter to the editor}

Dear Editor,

We appreciate the letter by renowned electron microscopist Alain Brisson in response to our article. As stated in his letter, "The aim of an EM study is to provide a faithful description of a sample". In the case of electron microscopy, the faithful description of a sample is based on the obtained images. Sources of variation contributing to the obtained images are (1) sample heterogeneity ("the morphology and size distribution of $E V s$, the presence or absence of nonvesicular particles and aggregates"), (2) the preparation protocol ("complex and poorly controlled processes"), and (3) the operator.

When influences of sample heterogeneity and preparation protocol were controlled, operator-selected images showed less variation than images taken at predefined locations. This finding is the result of "confirmation bias", which is defined as "evaluating evidence that supports one's preconceptions differently from evidence that challenges these convictions" [1,2]. In the case of EM, the operator looks for image locations that confirm the expectation. While it is common in EM to assume that the operator influence on the study outcome is negligible, this assumption is at odds with the results of our study and the knowledge of confirmation bias. Therefore, in our view the "faithful description of a sample" is best reflected by images taken at predefined locations.

\section{Disclosure statement}

No potential conflict of interest was reported by the authors.

\section{Funding}

This work was supported by the Stichting voor de Technische Wetenschappen [VENI 13681]; Stichting voor de Technische Wetenschappen [Perspectief CANCERID 14198].

\section{References}

[1] Kaptchuk TJ. Effect of interpretive bias on research evidence. BMJ. 2003;326:1453.

[2] Tversky A, Kahneman D. Judgment under uncertainty: heuristics and biases. Science. 1974;185:1124-1131.

L. G. Rikkert

Department of Medical Cell BioPhysics, University of Twente, Enschede, The Netherlands Laboratory of Experimental Clinical Chemistry, Academic Medical Center, University of Amsterdam, Amsterdam, The Netherlands

Vesicle Observation Center, Academic Medical Center, University of Amsterdam, Amsterdam, The Netherlands

ㅂ..g.rikkert@amc.uva.nl

R. Nieuwland

Laboratory of Experimental Clinical Chemistry, Academic Medical Center, University of Amsterdam, Amsterdam, The Netherlands Vesicle Observation Center, Academic Medical Center, University of Amsterdam, Amsterdam, The Netherlands

L. W. M. M. Terstappen Department of Medical Cell BioPhysics, University of Twente, Enschede, The Netherlands

F. A. W. Coumans Vesicle Observation Center, Academic Medical Center, University of Amsterdam, Amsterdam, The Netherlands Department of Biomedical Engineering and Physics, Academic Medical Center, University of Amsterdam, Amsterdam, The Netherlands 